\title{
Betamethasone Dipropionate
}

National Cancer Institute

\section{Source}

National Cancer Institute. Betamethasone Dipropionate. NCI Thesaurus. Code C47963.

The 17,21-dipropionate ester of betamethasone, a synthetic glucocorticoid with metabolic, immunosuppressive and anti-inflammatory actions. Betamethasone dipropionate binds to specific intracellular glucocorticoid receptors and subsequently binds to DNA to modify gene expression. The synthesis of certain anti-inflammatory proteins is induced while the synthesis of certain inflammatory mediators is inhibited. As a result, there is an overall reduction in chronic inflammation and autoimmune reactions. 